\title{
Correction to: Cabinetmakers' Workplace Mathematics and Problem Solving
}

\author{
Laia Saló i Nevado ${ }^{1}$. Leila Pehkonen ${ }^{1}$
}

Published online: 12 March 2018

(C) Springer Science+Business Media B.V., part of Springer Nature 2018

\section{Correction to: Vocations and Learning https://doi.org/10.1007/s12186-018-9200-8}

Unfortunately, the original version of this article was published online with error. The Figures and Pictures was mixed up.

The corrected Pictures 1 and 2 and Figures 1 and 2 are shown in the next page. The original article has been corrected.

The online version of the original article can be found at https://doi.org/10.1007/s12186-018-9200-8

Leila Pehkonen

leila.pehkonen@helsinki.fi

Laia Saló i Nevado

laia.salo@helsinki.fi

1 Faculty of Educational Sciences, University of Helsinki, Siltavuorenpenger 5, PL9, 00014 Helsinki, Finland 


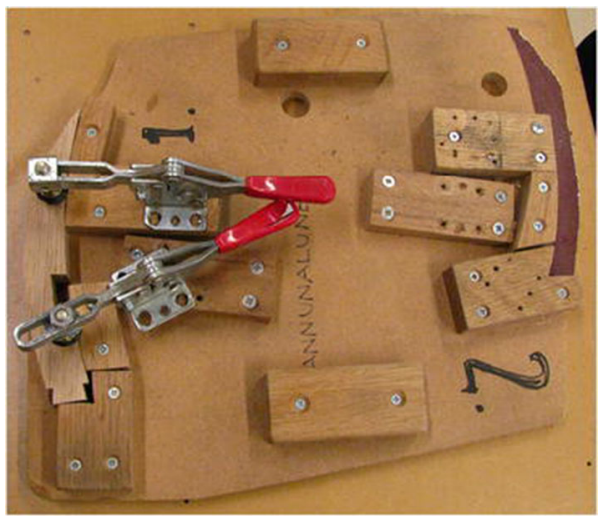

Picture 1 Two jigs in one board (numbered) for making the arms of a trivet. In jig number two it can be seen how is the piece of wood fastened

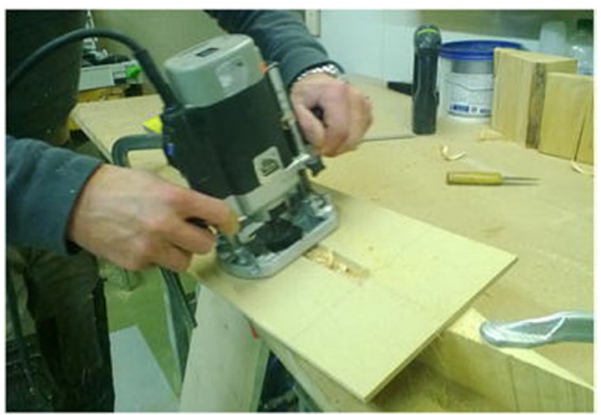

Picture 2 Jig to guide the router when making a hole. In the picture, the router is being guided by the jig (wooden plank with a hole) 


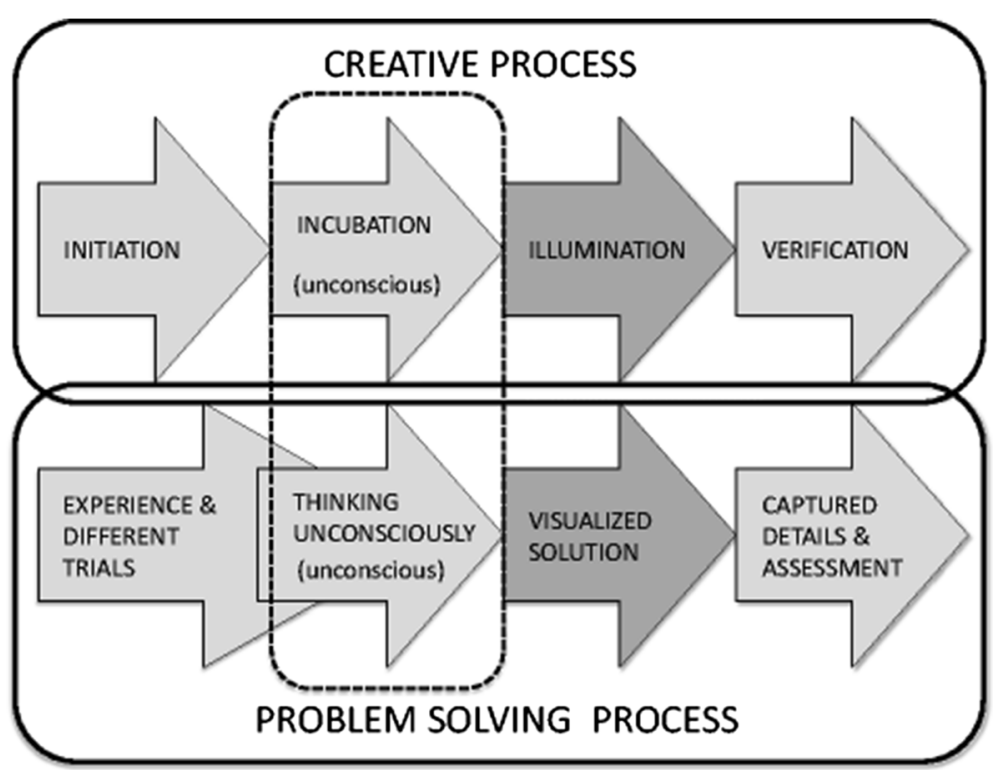

Fig. 1 According to our data, the stages of both the creative process and the problem solving process seem to be analogous

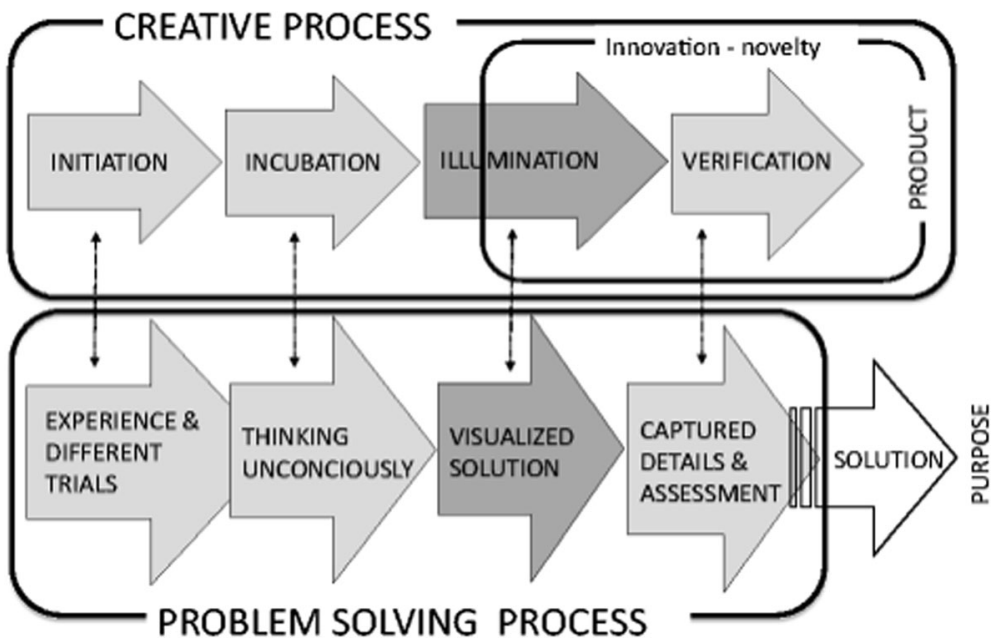

Fig. 2 Problem solving process and creative process based on our data 